\title{
Desarrollo internacional de las obligaciones le- gales de las empresas respecto de los derechos humanos
}

\author{
JAVIER MUJICA PETIT*
}

Al fin y al cabo, somos lo que hacemos para cambiar lo que somos.

Eduardo Galeano

If you are neutral in situations of injustice, you have chosen the side of the oppressor.

Desmond Tutu

SUMARIO: INTRODUCCIÓN.- I. LOS DERECHOS HUMANOS COMO LÍMITE AL EJERCICIO DEL PODER.- II. LA AMPLIACIÓN DE LA COMPRENSIÓN SOBRE QUIÉNES ESTÁN OBLIGADOS A RESPETAR Y PROTEGER LOS DERECHOS HUMANOS.- III. EL DERROTERO DE LOS INTENTOS POR IMPLEMENTAR LA RESPONSABILIDAD SOCIAL Y LEGAL DE LAS EMPRESAS EN MATERIA DE DERECHOS HUMANOS.- IV. EL DEBER DE LAS EMPRESAS DE RESPETAR, PROTEGER Y REMEDIAR.- V. ALGUNAS REFLEXIONES FINALES.

\section{INTRODUCCIÓN}

En el presente artículo se pasará revista al proceso de debates y consensos que se han ido construyendo a lo largo de las últimas décadas respecto de cuatro cuestiones fundamentales: $i$. la responsabilidad que las empresas tienen en virtud del Derecho internacional de derechos humanos; ii. la aplicación universal de estas responsabilidades —más allá de su lugar de origen o el de realización de sus actividades - y la gama de derechos que estas responsabilidades abarcan; iii. el deber de los Estados de prevenir, sancionar y remediar los abusos que las empresas cometan en perjuicio de las personas, las comunidades y/o el medio ambiente; y, finalmente, iv. la necesidad de que, dado el carácter transnacional del problema, se monitoree y asegure que el comportamiento de las empresas, más allá de sus fronteras nacionales, se ajuste a los requerimientos impuestos por su obligación de respetar los derechos humanos.

Se trata de un debate por cierto inacabado, en el que, no obstante, se cuenta ya con suficientes elementos de juicio como para proponer e instrumentalizar medidas de política pública, nacional e internacional que aseguren la conformidad del desempeño de las empresas con las obligaciones mínimas que derivan de los tratados internacionales de derechos humanos. Estas propuestas se resumen en la parte final del artículo.

\footnotetext{
* Es secretario ejecutivo del Centro de Políticas Públicas y Derechos Humanos - Perú EQUIDAD y representante de la Federación Internacional de Derechos Humanos ante la Organización de Estados Americanos.
} 


\section{LOS DERECHOS HUMANOS COMO LÍMITE AL EJERCICIO DEL PODER}

Al hablar de «derechos humanos», nos referimos a la dignidad de la persona humana. Y cuando hablamos de «dignidad de la persona humana», nos referimos, esencialmente, a todo lo que le permite disfrutar integralmente de su condición de ser humano.

Las personas viven dignamente cuando disfrutan de libertad, seguridad e igualdad; pero también cuando disponen de vivienda, educación, salud y alimentación adecuadas; cuando reciben por su trabajo una retribución justa o cuando, ante el riesgo de la pérdida de sus medios de vida, su supervivencia es asegurada mediante un sistema de seguridad social.

Esta es la razón por la que, fundados en principios éticos que usualmente han sido positivados en leyes, constituciones y tratados internacionales, los derechos humanos han integrado y comprenden todas aquellas cualidades de la vida en el ámbito civil, político, económico, social, cultural o ambiental a las que todos tenemos derecho, sin distinción alguna, ya sea por motivos de edad, género, etnia, religión, origen nacional, condición económica y social, preferencia sexual o por cualquier otra condición.

Como personas, todos podemos reclamar respeto a nuestros derechos humanos por el solo hecho de formar parte de la especie humana o, como dice la Declaración Universal de Derechos Humanos, por formar parte «de la familia humana» ${ }^{1}$. Y en la medida en que afectan directamente nuestra calidad de vida, su defensa y promoción es considerada fundamental para todos los seres humanos.

Los derechos humanos comparten un conjunto de características intrínsecas, que incluyen las de considerárselos innatos o inherentes ${ }^{2}$, inalienables e intransferibles ${ }^{3}$, universales ${ }^{4}$, indivisibles ${ }^{5}$, interdependientes $^{6}$, inviolables ${ }^{7}$ y también plenamente exigibles ${ }^{8}$.

1 En el Preámbulo de la Declaración Universal de Derechos Humanos de 1948 se lee: «[...] la libertad, la justicia y la paz en el mundo tienen por base el reconocimiento de la dignidad intrínseca y de los derechos iguales e inalienables de todos los miembros de la familia humana [...]".

2 Esto es, que le pertenecen a la persona por su condición de ser humano.

3 Vale decir que no solo nadie puede, sin renunciar a su dignidad, renunciar a sus derechos y libertades fundamentales, sino que tampoco los Estados pueden disponer de los derechos de sus ciudadanos sin afectar su dignidad. Pueden, es verdad, en circunstancias extremas y justificadas, limitarlos o suspenderlos, pero en ningún caso alienarlos -es decir, eliminarlos o extinguirlos-.

4 Los derechos humanos no derivan del hecho de que hombres y mujeres sean oriundos de un determinado Estado, sino que tienen como fundamento los atributos de la persona humana.

5 Esto quiere decir que no es posible garantizar la vigencia de unos derechos con prescindencia o, peor aún, con desmedro de otros.

6 Dado que todos los derechos humanos se consideran fundamentales, no es posible establecer una jerarquía entre ellos, y menos creer que unos son más importantes que otros. Su pertenencia a una totalidad cuyo propósito es asegurar la dignidad humana explica su indivisibilidad e interdependencia.

7 Nadie está autorizado a atentar, lesionar o destruir los derechos humanos.

8 Los dominios, prerrogativas o atributos que los derechos humanos reconocen en las personas imponen obligaciones a los Estados que estos no pueden rehuir. Por el contrario, el Estado se encuentra obligado a adoptar medidas oportunas y adecuadas para garantizar la plena realización de los derechos. 
Por esta razón, para que un sistema jurídico pueda ser considerado «justo», dice Federico Laporta ${ }^{9}$, debe reconocer estos derechos y su carácter jurídicamente vinculante para todos los Estados. En esta misma medida, para asegurar que estos derechos trasciendan del nivel de la utopía, los Estados — dice el Preámbulo de la Carta de las Naciones Unidashan asumido «el deber de contribuir a crear condiciones bajo las cuales puedan mantenerse la justicia y el respeto a las obligaciones emanadas de los tratados y otras fuentes del derecho internacional relativas a los derechos humanos, promoviendo el progreso y la elevación constante de los niveles de vida dentro de un concepto lo más amplio posible de libertad $»^{10}$.

Dicho deber es reiterado por los artículos 55 y 56 de la misma Carta de las Naciones Unidas ${ }^{11}$, los cuales atribuyen a los Estados el deber de promover los más altos estándares de vida, trabajo permanente y condiciones de progreso y desarrollo económico y social para todos y todas; de respetar y garantizar la observancia universal de los derechos humanos y las libertades fundamentales; así como de adoptar medidas — por sí mismos o por medio de la cooperación internacional- para concretar estos objetivos.

Así pues, cuando ratifican los tratados internacionales de derechos humanos, los Estados asumen la responsabilidad primaria de asegurar - a través de todas sus instancias y niveles de gobierno, así como del conjunto de los poderes públicos que lo integran — que estos derechos sean respetados, protegidos y cumplidos plenamente. Y esa responsabilidad alcanza también a todos los componentes de la sociedad en general, lo que incluye a las instituciones internacionales, los individuos, las familias, las empresas y la comunidad.

Estados y autoridades encuentran legitimidad y justificación única y exclusivamente en la medida en que sean capaces de respetar, de promover y de garantizar estos derechos fundamentales integralmente considerados. Y para cumplir con este propósito, el Derecho internacional de los derechos humanos ha impuesto un conjunto de límites al ejercicio abusivo del poder público.

9 LAPORTA, Francisco. «Ética y Derecho en el pensamiento contemporáneo». En Historia de la Ética. Tomo III. Barcelona: Editorial Crítica, 1989, p. 292.

10 Preámbulo de la Carta de las Naciones Unidas, firmada el 26 de junio de 1945 en San Francisco, Estados Unidos.

11 El artículo primero de la Carta de las Naciones Unidas (1945) señala que el desarrollo y el estímulo del respeto a los derechos humanos y a las libertades fundamentales de todos, sin hacer distinción por motivos de raza, sexo, idioma o religión, constituye una piedra fundamental y un medio privilegiado de las Naciones Unidas para el cumplimiento de sus objetivos fundamentales. El artículo 55 (c) de la carta establece que las Naciones Unidas alentarán «el respeto universal a los derechos humanos y a las libertades fundamentales de todos, sin hacer distinción por motivos de raza, sexo, idioma o religión, y la efectividad de tales derechos y libertades". Y el artículo 56 agrega el compromiso de todos sus miembros a «tomar medidas conjunta o separadamente, en cooperación con la Organización, para la realización de los propósitos consignados en el Artículo 55». Para que no queden dudas sobre la primacía de estos compromisos, el artículo 103 confirma su preeminencia en los siguientes términos: «En caso de conflicto entre las obligaciones contraídas por los Miembros de las Naciones Unidas en virtud de la presente Carta y sus obligaciones contraídas en virtud de cualquier otro convenio internacional, prevalecerán las obligaciones impuestas por la presente Carta».

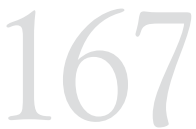

DESARROLLO INTERNACIONAL DE LAS OBLIGACIONES LEGALES DE LAS EMPRESAS RESPECTO DE LOS DERECHOS HUMANOS 
En efecto, el Derecho internacional de los derechos humanos ha desarrollado un amplio conjunto de parámetros sobre lo que los Estados están impedidos de hacer y, al mismo tiempo, un espectro amplio de mandatos que precisan lo que debe hacer para que sus políticas públicas sean respetuosas hacia los derechos humanos.

Los Estados deben, en primer lugar, respetar los derechos humanos, y esta obligación exige que se abstengan de interferir en el goce de estos derechos. Tienen la obligación, además, de proteger los derechos humanos, y esta obligación demanda que prevengan su violación por parte de terceros. Y por «terceros» habremos de entender a particulares, grupos, empresas y otras entidades, así como a quienes obren en su nombre.

La obligación de proteger comprende, entre otras cosas, el deber de adoptar las medidas legislativas o de otra índole que sean necesarias y efectivas para impedir, por ejemplo, que terceros denieguen el acceso en pie de igualdad a los distintos componentes de un determinado derecho, o que se impongan condiciones o suministren prestaciones que no sean coherentes con dicho derecho.

La obligación de cumplir con los derechos humanos exige que los Estados adopten las medidas legislativas, administrativas, presupuestarias, judiciales y/o de cualquier otra naturaleza que sean adecuadas, así como otras medidas, para asegurar o facilitar el logro de los derechos. Esta obligación puede, a su vez, subdividirse en tres obligaciones concurrentes: las obligaciones de facilitar, de promover y de garantizar.

La obligación de facilitar exige que los Estados partes adopten medidas positivas que permitan y ayuden a los particulares y las comunidades a ejercer sus derechos ${ }^{12}$. La obligación de promover impone a los Estados el deber de adoptar medidas para velar por que se impartan educación y sensibilización adecuadas en relación con el ejercicio de los derechos, particularmente en zonas rurales y zonas urbanas desfavorecidas o entre las minorías lingüísticas o de otro tipo. Los Estados tienen, asimismo, la obligación de hacer efectivos o de garantizar los derechos en los casos en que los particulares o los grupos no están en condiciones, por razones ajenas a su voluntad, de ejercitarlos por sí mismos con los medios a su disposición.

La obligación de garantizar exige que los Estados organicen todo el aparato gubernamental y, en general, todas las estructuras a través de las cuales se manifiesta el ejercicio de poder político, de manera que sean capaces de asegurar jurídicamente el libre y pleno disfrute de los derechos humanos.

12 Esta obligación comprende, entre otras cosas, la necesidad de reconocer en grado suficiente este derecho en el ordenamiento político y jurídico nacional, de preferencia mediante la aplicación de las leyes; adoptar una estrategia y un plan de acción nacionales dirigido a asegurar el ejercicio del derecho; velar por que los medios y/o prestaciones relacionadas con este sean adecuados, accesibles y asequibles para todos. 
A las obligaciones anteriores se suma la de no discriminación, de conformidad con la cual, además del deber de asegurar a todas las personas un trato igualitario y no discriminatorio, tanto en materia de derechos civiles y políticos como de derechos económicos, sociales y culturales, la obligación del Estado se extiende a la adopción de medidas especiales -incluidas medidas legislativas y políticas diferenciales - en favor de las mujeres y en resguardo de otros grupos en situación de vulnerabilidad y/o de sectores estructural o históricamente desprotegidos. Para cumplir con esta obligación, los Estados tienen el deber de identificar y priorizar a los grupos sociales marginados y excluidos, sin que por ello se descuide o se diluya alguna de las demás obligaciones que han asumido al ratificar los tratados de derechos humanos.

Para hacer efectivos estos derechos, además, los Estados tienen el deber de adoptar medidas inmediatas, de modo que estas se concreten en un plazo razonablemente breve desde el momento mismo en que ratifican los instrumentos internacionales referidos a los derechos humanos. Tales medidas deben consistir en actos concretos, deliberados y orientados lo más claramente posible hacia la satisfacción de la totalidad de los derechos; cuando los Estados incumplan con esta obligación, tienen el deber de justificar su inactividad, demora o desviación en el cumplimiento de tales objetivos.

En todo caso, los Estados tienen siempre la obligación fundamental de asegurar como mínimo la satisfacción de niveles esenciales de cada uno de los derechos; y, en la medida en que se han obligado a mejorar la situación de los derechos humanos, están simultáneamente prohibidos de reducir los niveles de protección ya otorgados a ellos o, en su caso, de derogar los derechos ya existentes, sin una justificación suficiente.

Solo en la medida en que las autoridades definan sus políticas con arreglo a los estándares de derechos humanos antes referidos, podrá evitarse que el ejercicio del poder público se manifieste de manera discrecional o arbitraria.

\section{LA AMPLIACIÓN DE LA COMPRENSIÓN SOBRE QUIÉNES ESTÁN OBLIGADOS A RESPETAR Y PROTEGER LOS DERECHOS HUMANOS}

Sabido es que el ejercicio del poder sin limitación alguna conduce siempre a las peores formas de maltrato de la dignidad humana; y así ha ocurrido a lo largo de nuestra historia a través de genocidios, persecuciones, prácticas discriminatorias o graves atentados contra la libertad en todas sus manifestaciones.

Para evitar que se produzcan estas situaciones, el sistema internacional de protección de los derechos humanos ha conducido, especialmente después de la Segunda Guerra Mundial, un notable esfuerzo por definir

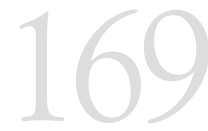

DESARROLLO INTERNACIONAL DE LAS OBLIGACIONES LEGALES DE LAS EMPRESAS RESPECTO DE LOS DERECHOS HUMANOS 
quiénes son responsables de garantizar estos derechos: se trata, en primera instancia, de los Estados.

En primer lugar, porque son ellos quienes tienen el monopolio del poder y quienes, por la misma razón, se ven con mayor frecuencia tentados a ejercerlo sin límites. Y ello obliga a vigilarlos constantemente y a tratar de frenar, cuando se presentan, dichos impulsos.

Los Estados son responsables de garantizar los derechos humanos, además, por el hecho de que son ellos quienes, al suscribir voluntariamente los tratados internacionales que los reconocen, se han sometido - también voluntariamente - a las obligaciones que tales tratados han establecido.

Lo anterior no significa, sin embargo, que los Estados sean los únicos actores concernidos por el deber de respetar y promover los derechos humanos. La razón de ello estriba en que los Estados no son los únicos cuyo poder debe ser limitado para salvaguardar la dignidad humana. En efecto, todos somos testigos de la forma en que las actuales dinámicas de globalización económica vienen intensificando la interdependencia entre empresas, los individuos y las instituciones de un enorme número de países alrededor de todo el planeta. Esta interdependencia ha traído enormes ventajas para quienes se desplazan alrededor de las esferas de la inversión y el comercio ${ }^{13}$, pero, a la vez, han ampliado, hasta niveles terriblemente exacerbados, las dramáticas inseguridades sociales y económicas en que viven las cuatro quintas partes de los habitantes de la Tierra.

Lo anterior incluye la inseguridad en los empleos y en los ingresos, el incremento de la pobreza rural y urbana, el crecimiento de la desigualdad entre ricos y pobres, la erosión de la calidad de vida de las personas como efecto de la degradación ambiental, la limitación de los gastos del sector público en servicios sociales que muchas veces son total o parcialmente —o directa o encubiertamente — privatizados, las regresiones en la equidad de género y el crecimiento de las vulnerabilidades que sufren los sectores excluidos o marginalizados en nuestras sociedades.

Estos fenómenos se suman a otras inseguridades que derivan de factores estructurales o institucionales, tales como el papel subordinado y marginal que históricamente le ha sido reservado a nuestras economías y sociedades en la división internacional del trabajo o el correlativo incremento del poder de las corporaciones transnacionales ${ }^{14} \mathrm{e}$

13 Por ejemplo, ampliando el desarrollo de economías de escala —unificando la producción y otras actividades en dos o más países-, reduciendo el costo de los factores y flexibilizando los procesos productivos - trasladando la manufactura u otras partes del proceso productivo a terceros países con costos más baratos-, concentrando la producción — remplazando la multiplicidad de modelos locales por productos estandarizados «globalmente»-, aumentando el poder negociador de las empresas mediante la amenaza los a proveedores, trabajadores y gobiernos, con el potencial traslado de la producción a otros países, etcétera.

14 El término "corporación transnacional» enfatiza el hecho de que se trata, usualmente, de una corporación que opera en más de un país, con una sede y un estatuto jurídico incorporado en la legislación nacional del Estado de origen. 
instituciones internacionales, tales como la Organización Mundial del Comercio (OMC), el Fondo Monetario Internacional (FMI) o el grupo del Banco Mundial (BM).

Como resultado, hoy más que nunca, la realización de los derechos humanos está estrechamente ligada a los movimientos de la economía global. Es un contexto en el que las empresas pueden afectar, tanto positiva como negativamente, la realización de la dignidad humana, y de los derechos y de las libertades fundamentales.

Ejemplo de ello son los derechos de los trabajadores. La protección de estos derechos cuenta con una recepción en el Derecho internacional tan temprana como 1919, cuando la Organización Internacional del Trabajo (OIT) adoptó su Convenio 1 dedicado a la limitación de la jornada de trabajo ${ }^{15}$. De ahí en más, el Derecho internacional de los derechos humanos generó una amplia provisión de protecciones vinculadas al trabajo que limitan, en muchos sentidos, el poder de las empresas.

Por ejemplo, la Declaración de la OIT sobre los Principios y Derechos Fundamentales en el Trabajo ${ }^{16}$ es vinculante para todos los Estados partes de la organización. Esta establece cuatro normas fundamentales sobre derechos laborales:

i. la libertad de asociación y el reconocimiento efectivo del derecho a la negociación colectiva;

ii. la eliminación de toda forma de trabajo forzoso u obligatorio;

iii. la abolición efectiva del trabajo infantil; y

iv. la eliminación de la discriminación en materia de empleo y ocupación.

Y a estos derechos laborales básicos, el Derecho internacional de los derechos humanos ha sumado muchos otros más:

- el derecho de toda persona a trabajar, lo que comprende el derecho a tener la oportunidad de ganarse la vida mediante un trabajo libremente escogido y aceptado ${ }^{17}$;

- al goce de condiciones de trabajo equitativas y satisfactorias que le aseguren, en especial, una remuneración que proporcione como mínimo a todos los trabajadores un salario equitativo e igual por trabajo de igual valor, sin distinciones de ninguna especie, y en particular que asegure a las mujeres condiciones de trabajo no inferiores a las de los hombres, con salario igual por trabajo igual;

15 Adoptado el 29 de octubre de 1919, el Convenio 1 de la OIT fue aprobado para limitar la jornada de trabajo -ocho horas por día y 48 por semana, salvo las excepciones previstas en el mismo convenio-

$16 \mathrm{La}$ Declaración de la OIT relativa a los principios y derechos fundamentales en el trabajo fue adoptada en 1998 y es la expresión del compromiso de los gobiernos y de las organizaciones de empleadores y de trabajadores de respetar y defender los valores humanos fundamentales que son de vital importancia para nuestras vidas en el plano económico y social.

17 Pacto Internacional de Derechos Económicos, Sociales y Culturales (PIDESC), artículo 6.1. 
- condiciones de existencia dignas para ellos y para sus familias;

- seguridad e higiene en el trabajo;

- igual oportunidad para todos de ser promovidos, dentro de su trabajo, a la categoría superior que les corresponda, sin más consideraciones que los factores de tiempo de servicio y capacidad;

- el descanso, el disfrute del tiempo libre, la limitación razonable de las horas de trabajo y las variaciones periódicas pagadas, así como la remuneración de los días festivos ${ }^{18}$.

Millones de trabajadores en todo el mundo son empleados por empresas grandes, medianas y pequeñas, y su sacrificada labor genera ganancias a sus propietarios, al tiempo que impulsa las economías locales y nacionales. Los salarios que las empresas pagan a sus trabajadores no solo les permite ganarse la vida y satisfacer sus necesidades básicas y las de sus familias, sino generar condiciones para que puedan satisfacer de manera integral sus derechos económicos, sociales y culturales a la vivienda, la educación, la salud, la alimentación, la protección de la familia o el disfrute de los beneficios de la cultura, la ciencia y la tecnología. Como consecuencia de ello, además de proporcionar legítimas ganancias a sus propietarios, la actuación de estas empresas cumple un papel positivo en la sociedad.

Empero, es evidente que en no pocas ocasiones, mientras esto sucede, algunas de estas empresas lesionan la dignidad de sus trabajadores y sus familias al contratar menores, al enrolar trabajadores de manera forzosa o al engancharlos a través de deudas, al reprimir el ejercicio de las libertades sindicales, al pagar remuneraciones diminutas, al imponer condiciones de trabajo insalubres o inseguras y/o al cometer o tolerar múltiples formas de discriminación en el trabajo.

Pueden, además, llevar a cabo sus actividades de manera perjudicial para el medioambiente y afectar, con ello, el bienestar de las personas y de las comunidades con las que se relacionan, así como lesionar directamente múltiples derechos, como el derecho a la vida, a la salud, a la alimentación, al agua, etcétera. En no pocas ocasiones, además, estas mismas empresas pueden también violar la integridad física y psicológica de las personas, y afectar con ello, y de múltiples maneras, los derechos a la vida, la libertad y la seguridad de las personas.

La participación directa o cómplice de las empresas y/o de sus agentes - a través de terceros (por ejemplo entidades paramilitares) o de su compromiso con gobiernos autoritarios en contextos de ejecuciones extrajudiciales, esclavitud y trabajo forzoso, tortura y tratos y/o castigos crueles, inhumanos o degradantes - puede acabar por comprometerlas en crímenes internacionales. 
Su actividad puede afectar, también, los derechos de los pueblos indígenas y limitar, en consecuencia, su derecho a determinar libremente su desarrollo económico, social y cultural, o las garantías colectivas de sus derechos humanos y, con ello, su propia supervivencia. En otras palabras, dicha actividad podría afectar su derecho a la tierra y a sus recursos y violar su derecho a dar su consentimiento previo, libre e informado en toda forma de intervención en su hábitat, lo cual afectaría sus intereses y sus derechos a la salud, al agua y a la alimentación, a la vivienda colectiva y a la propiedad, a la cultura, a la vida y a los recursos efectivos que los protejan de interferencias en el ejercicio de sus derechos fundamentales.

Desafortunadamente, muchas de estas violaciones ocurren en el mundo y se producen en un contexto en el que los Estados incumplen con demasiada frecuencia con su deber de respetar y proteger los derechos humanos de las personas sometidas a su jurisdicción. Tan problemático como lo anterior resulta que, muchas veces, las empresas no se sientan obligadas a respetar las garantías vinculadas con los derechos humanos, aun sabiendo que no pueden traspasar los límites que salvaguardan el disfrute de los derechos humanos.

La ausencia de mecanismos efectivos para evitar estas violaciones o para reparar los daños producidos y compensar a las víctimas refuerza la impunidad con que estas prácticas suceden. Ello, a su vez, refuerza la preocupación de la comunidad - léase trabajadores, consumidores, ambientalistas, inversionistas, mujeres, comunidades afectadas, pueblos indígenas, etcétera - por encontrar mecanismos que permitan responsabilizar a las empresas por sus actos, cuando estos suponen una violación a los derechos humanos.

El Derecho internacional de los derechos humanos impone a los Estados, como dijimos, el deber de proteger a todas las personas sometidas a su jurisdicción frente a las violaciones a los derechos humanos por actores no estatales, incluidas las empresas. Y esta obligación les impone el deber de impedir e investigar los abusos que se cometan, o que puedan cometerse, así como sancionar a los culpables y proporcionarles a todas las personas un recurso efectivo, sencillo y breve que las proteja de las amenazas o de las violaciones a sus derechos fundamentales.

Los Estados fallan al cumplir con esta obligación, no obstante, porque carecen de regulaciones y procedimientos que permitan enjuiciar tales violaciones y hacerlas pasibles de sanción y de medidas de reparación. Fallan en su deber de proteger porque también, y en no pocas ocasiones, carecen de capacidades institucionales y de voluntad política para ello. Están demasiado influidos por los intereses económicos que encarnan los violadores a los derechos humanos o, simple y llanamente, porque se trata de regímenes abusivos, autoritarios y/o corruptos, cómplices de las violaciones producidas por las empresas. El ejemplo del gobierno de

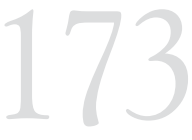

DESARROLLO INTERNACIONAL DE LAS OBLIGACIONES LEGALES DE LAS EMPRESAS RESPECTO DE LOS DERECHOS HUMANOS 
Alberto Fujimori en el Perú de los años noventa es altamente ilustrativo al respecto.

Sin embargo, no todo es responsabilidad de los Estados. Las empresas tienen también la obligación de respetar los derechos humanos. Aunque los primeros tienen la responsabilidad primaria de promover, cumplir y fortalecer los derechos humanos, cada vez es más claro que las empresas y corporaciones transnacionales comparten esta obligación.

De hecho, en 1948, el Preámbulo de la Declaración Universal de los Derechos Humanos (DUDH) estableció que «tanto los individuos como las instituciones, inspirándose constantemente en ella, promuevan, mediante la enseñanza y la educación, el respeto a estos derechos y libertades, y aseguren, por medidas progresivas de carácter nacional e internacional, su reconocimiento y aplicación universales y efectivos» (énfasis añadido).

Por «las instituciones», la DUDH se refiere claramente a las empresas. La obligación de respetar «estos derechos y libertades» comporta, cuanto menos, que las empresas los promuevan, que aseguren su reconocimiento y su aplicación universales, y que se abstengan de violar o de afectar negativamente su disfrute. Las empresas, en otras palabras, están impedidas de «dañar» los derechos humanos.

\section{EL DERROTERO DE LOS INTENTOS POR IMPLEMENTAR LA RESPONSABILIDAD SOCIAL Y LEGAL DE LAS EMPRESAS EN MATERIA DE DERECHOS HUMANOS}

Como ha sido mencionado, las empresas pueden participar directamente en violaciones a los derechos humanos cuando contratan niños o personas para la realización de trabajos forzosos, cuando imponen inseguras condiciones de trabajo, cuando aplican prácticas discriminatorias basadas en el género o en la raza de las personas involucradas, cuando omiten pagar horas extras o beneficios sociales a sus trabajadores, cuando aplican prácticas antisindicales, cuando contaminan el ambiente, el agua o las fuentes de alimentos, cuando propician la muerte de personas a través de sus agentes de inseguridad, etcétera.

Pueden participar también en violaciones a los derechos humanos como cómplices y, asociadas a gobiernos autoritarios o corruptos, pueden hacerlo en violaciones al derecho a la vida y la seguridad de las personas, sean estos, por ejemplo, sindicalistas miembros de las comunidades o simplemente manifestantes. Y pueden hacerlo, también, a través del apoyo financiero o logístico a quienes perpetran dichos actos.

Asimismo, pueden hacerlo cuando se comprometen en actos de corrupción que socavan los recursos que un Estado debería ocupar en la atención de los derechos de sus ciudadanos, cuando limitan el acceso del público a la información sobre sus actividades - y a sus respectivas 
consecuencias - o cuando se benefician de la concesión de tierras y recursos naturales en detrimento de las comunidades locales o de los pueblos indígenas involucrados.

Las empresas pueden violar los derechos en estas formas y en muchas otras. De hecho, lo han hecho en múltiples oportunidades. Casos como el de la ITT y otras compañías estadounidenses comprometidas en el sangriento golpe de Estado que derrocó al presidente Salvador Allende en Chile, como el de los sobornos de la compañía inglesa Lockheed a altos funcionarios para hacerse ilegalmente de contratos militares en Japón, como el del compromiso cómplice de la compañía Shell con las violaciones a los derechos humanos producidas por las autoridades militares de Nigeria, como el de la relación de la empresa Coca-Cola con grupos paramilitares en Colombia, como el de la empresa chilena Luchetti con Montesinos en Perú, como el del desastre químico y de la brutal contaminación generada por la empresa Union Carbide en la localidad de Bhopal, en la India, o como el de los crímenes perpetrados por la contratista estadounidense Blackwater Security Consulting en Irak son apenas algunos reflejos de lo que esto puede implicar.

En vista de ello, un amplio debate se ha desplegado a nivel internacional en un intento de inducir a las corporaciones multinacionales a respetar los derechos humanos, lo que ha llevado a que, durante las últimas dos décadas, sean ya más de doscientas las iniciativas relacionadas con la responsabilidad de las corporaciones en materia de derechos humanos que han sido puestas en práctica ${ }^{19}$.

Estas iniciativas se han desarrollado, por una parte, a través de organismos multilaterales concernidos por el impacto de las actividades de empresas multinacionales y comerciales sobre los derechos humanos y, en un plano diferente, a través de iniciativas promovidas fundamentalmente por actores no estatales, centrados en el desarrollo de instrumentos de autorregulación.

En adelante nos ocuparemos de las primeras, esto es, principalmente de iniciativas como el Proyecto de Código de Conducta de la ONU sobre Empresas Transnacionales, la Declaración Tripartita de Principios sobre las Empresas Multinacionales y la Política Social de la OIT, las Directrices de la Organización para la Cooperación y el Desarrollo Económico (OCDE) sobre Empresas Multinacionales (revisadas en 2001), el Pacto Global de Derechos Humanos de Naciones Unidas (2000) o las Normas sobre las Responsabilidades de las Empresas Transnacionales y otras Empresas Comerciales en la esfera de los Derechos Humanos. 
Al hacerlo, empezaremos diciendo que la preocupación sobre los impactos de las empresas transnacionales en materia de derechos humanos y el medioambiente no es nueva en el ámbito de las Naciones Unidas. De hecho, ya desde la década de 1970 la ONU ha venido tratando de ofrecer una respuesta de alcance internacional al creciente malestar público que la actuación de muchas empresas transnacionales ha generado en el ámbito de los derechos humanos.

Por su condición de único foro mundial cuyo objeto es defender y promover los derechos humanos, las Naciones Unidas se han convertido en el espacio natural de los esfuerzos para que las empresas asuman sus responsabilidades.

Así, en 1973 fue creada la Comisión de las Naciones Unidas sobre Empresas Transnacionales, producto de cuyo trabajo resultó la elaboración del Proyecto de Código de Conducta de la ONU sobre Empresas Transnacionale ${ }^{20}$, en 1983. El trabajo de esta comisión enfrentó, no obstante y desde el principio, como era de esperarse, una férrea resistencia de los países en los que la mayor parte de empresas transnacionales tiene sedes. Como consecuencia de ello, pese al amplio respaldo con que la iniciativa contaba en el seno de los países del Hemisferio Sur, el proyecto fue paulatinamente desbaratado.

En 1976, la Organización para la Cooperación y el Desarrollo Económico (OCDE), elaboró las Directrices para las Empresas Multinacionales, que incluía un articulado conjunto de recomendaciones dirigidas por los gobiernos a las transnacionales, repertorio amplio de principios y normas que, voluntariamente, debían integrar en su práctica empresarial.

Como señala el prólogo de las directrices:

La vocación de las Directrices es garantizar que las actividades de esas empresas se desarrollen en armonía con las políticas públicas, favorecer la base de confianza mutua entre las empresas y las sociedades en las que desarrollan su actividad, contribuir a mejorar el clima para la inversión extranjera y potenciar la contribución de las empresas multinacionales al desarrollo sostenible ${ }^{21}$.

Las recomendaciones de las directrices persiguen que las transnacionales ajusten sus prácticas a lo que en ellas se entiende como una «buena conducta empresarial». Y aunque están dirigidas, primordialmente, a las empresas implantadas en aquellos países que son adherentes a ellas ${ }^{22}$,

20 Véase el Proyecto de Código de Conducta de la ONU para Empresas Transnacionales de 1983. En $<$ http://www.juridicas.unam.mx/publica/librev/rev/jurid/cont/11/pr/pr7.pdf\&ei=dJ4ASo2WJJauNc7vp OEH\&usg=AFQjCNGH_mMoZmYBIV1Eqb92KP9WqdF3YA>.

21 OCDE. Líneas Directrices de la OCDE para Empresas Multinacionales, «Prólogo», párrafo 1.

22 Dichos países incluyen los treinta países de la OCDE: Austria, Bélgica, Canadá, Dinamarca, Francia, Alemania, Grecia, Islandia, Irlanda, Italia, Luxemburgo, Países Bajos, Noruega, Portugal, España, Suecia, Suiza, Turquía, Reino Unido, Estados Unidos, Japón, Finlandia, Australia, Nueva Zelanda, México, República Checa, Hungría, Polonia, Corea y República Eslovaca, además de Argentina, Brasil y Chile. 
también se aplican a las operaciones comerciales en todo el mundo. Las directrices ceden la responsabilidad final de su ejecución a las propias empresas.

En 1977, la OIT adoptó la Declaración Tripartita de Principios sobre las Empresas Multinacionales y la Política Social ${ }^{23}$, que, aunque careciendo de carácter legal vinculante como en el caso de las directrices, están enfocadas especialmente en los derechos de los trabajadores e instan a las empresas a respetar la Declaración Universal de Derechos Humanos y los demás pactos internacionales de derechos humanos, incluido un mecanismo que posibilita denunciar los abusos cometidos por las empresas contra estos derechos.

Aunque la Declaración Tripartita de la OIT contiene una cantidad más grande y precisa de recomendaciones relacionadas con asuntos laborales que las directrices, estas últimas cubren un rango más amplio de actividades empresariales, por lo que puede decirse, de cierta manera, que ambas se complementan.

En 1999, por otra parte, el Secretario General de la ONU presentó a la comunidad internacional el Pacto Mundial de las Naciones Unidas, conocido también como Global Compact: una iniciativa igualmente voluntaria, cuyo objeto es alinear a las empresas, las instituciones de las Naciones Unidas y las organizaciones de la sociedad civil con diez principios básicos en el área de los derechos humanos, los estándares laborales, el medio ambiente y la lucha contra la corrupción.

El Pacto Mundial planteó que las empresas transnacionales integren estos principios en sus actividades, tanto en su país de origen como en las operaciones que realizan alrededor del mundo. Al mismo tiempo, instó a que implementen actividades de apoyo a los objetivos de desarrollo de las Naciones Unidas y en particular respecto de los Objetivos de Desarrollo del Milenio (ODM).

Para concretarlos, el pacto les ofrece oportunidades de aprendizaje y de participación a través de mecanismos diversos, tales como la realización de diálogos sobre políticas, el entrenamiento en temas puntuales, la participación en redes locales y la generación de alianzas para llevar a cabo proyectos.

Es claro que, si los propósitos del Pacto Mundial se hubiesen cumplido, con seguridad el número de abusos contra los derechos humanos se habría reducido sustancialmente en el mundo. No obstante, el hecho clave de que estos carezcan de carácter imperativo, lo que significa que no deben ser obligatoriamente respetados, mostró — de la misma forma que en las iniciativas anteriores- que instrumentos como estos, con

DESARROLLO INTERNACIONAL DE LAS OBLIGACIONES LEGALES DE LAS EMPRESAS RESPECTO DE LOS DERECHOS HUMANOS 
todo lo importante que puedan ser, resultan insuficientes por sí mismos para prevenir y evitar tales abusos.

\begin{tabular}{|c|}
\hline $\begin{array}{l}\text { Pacto Mundial } \\
\text { Principios de derechos humanos }\end{array}$ \\
\hline $\begin{array}{l}\text { Derechos humanos } \\
\text { - Las empresas deben apoyar y respetar la protección de los derechos } \\
\text { humanos proclamados a nivel internacional. } \\
\text { - Deben evitar verse involucradas en abusos de los derechos humanos. }\end{array}$ \\
\hline $\begin{array}{l}\text { Estándares laborales } \\
\begin{array}{l}\text { - Las empresas deben respetar la libertad de asociación. } \\
\text { - Deben reconocer el derecho a la negociación colectiva. } \\
\text { - Deben procurar la eliminación de todas las formas de trabajo forzoso } \\
\text { y obligatorio, la abolición del trabajo infantil y la eliminación de la } \\
\text { discriminación respecto del empleo y de la ocupación. }\end{array}\end{array}$ \\
\hline 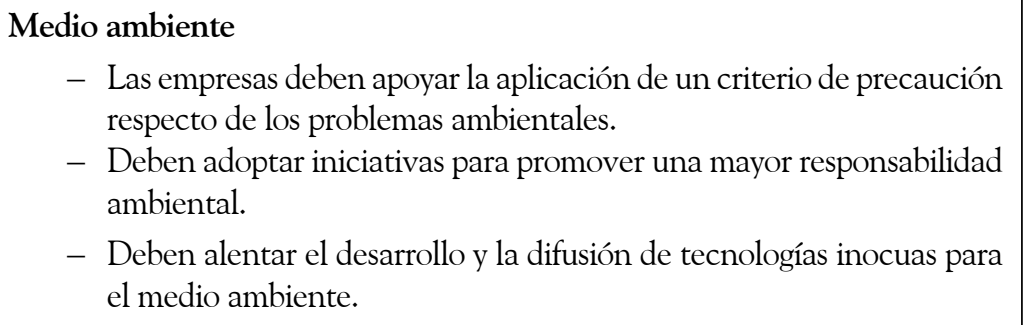 \\
\hline $\begin{array}{l}\text { Anticorrupción } \\
\text { - Las empresas deben actuar en contra de todas las formas de corrup- } \\
\quad \text { ción, incluidos la extorsión y el soborno. }\end{array}$ \\
\hline
\end{tabular}

Las discusiones al respecto continuaron. En agosto de 2003, tras un largo proceso de debate y consultas con sindicatos, empresas y $\mathrm{ONG}$, la Subcomisión de Promoción y Protección de los Derechos Humanos — entonces órgano asesor de la Comisión de Derechos Humanos de las Naciones Unidas, hoy Consejo de Derechos Humanos- aprobó un proyecto de instrumento denominado Normas sobre las Responsabilidades de las Empresas Transnacionales y otras Empresas Comerciales en la Esfera de los Derechos Humanos ${ }^{24}$. 
Además de reconocer el rol fundamental de los Estados en orden a garantizar los derechos humanos, las normas recurren a diversas fuentes para identificar una lista de responsabilidades clave de las empresas respecto de los derechos humanos; reconoce, asimismo, numerosos derechos que integran los tratados internacionales de derechos humanos: el derecho a la igualdad de oportunidades y a un trato no discriminatorio, el derecho a la seguridad de las personas, el respeto a la soberanía nacional y los derechos humanos civiles y políticos, así como de los derechos de los trabajadores, y los derechos económicos, sociales y culturales -incluidos los derechos al desarrollo, a la alimentación, la salud y la vivienda adecuadas, y al agua-. Además, presentaba previsiones destinadas a proteger a los consumidores y al medio ambiente.

Al precisar a quién concierne garantizar la vigencia de estos derechos, su artículo primero indica lo siguiente:

Los Estados tienen la responsabilidad primordial de promover y proteger los derechos humanos consagrados en la legislación internacional y nacional, asegurar que se cumplan, respetarlos y hacerlos respetar, incluso velando por que las empresas transnacionales y otras empresas comerciales respeten los derechos humanos. Dentro de sus respectivas esferas de actividad e influencia, las empresas transnacionales y otras empresas comerciales tienen la obligación de promover y proteger los derechos humanos consagrados en el Derecho internacional y en la legislación nacional, incluidos los derechos e intereses de los pueblos indígenas y otros grupos vulnerables, asegurar que se cumplan, respetarlos y hacerlos respetar.

Y para asegurar su cumplimiento, contemplaba un conjunto de mecanismos de verificación y rendición de cuentas:

Las empresas transnacionales y otras empresas comerciales serán objeto de una vigilancia y verificación periódicas por mecanismos nacionales y otros mecanismos internacionales y de las Naciones Unidas que ya existan o estén por crearse, en lo que respecta a la aplicación de estas Normas. Esa vigilancia será transparente e independiente y tendrá en cuenta la información que proporcionen las partes interesadas (incluidas las organizaciones no gubernamentales) y la información proveniente de denuncias de violaciones de las presentes Normas. Además, las empresas transnacionales y otras empresas comerciales realizarán evaluaciones periódicas de los efectos de sus propias actividades en los derechos humanos a la luz de las presentes Normas ${ }^{25}$.

Actualmente, las normas carecen de estructuras que se encarguen de velar por su cumplimiento. $Y$ aunque no sean vinculantes como tales, pese a que aluden a un gran número de instrumentos legales que sí lo son, complementan las iniciativas y los estándares internacionales sobre 
responsabilidad de las empresas transnacionales ya referidos. Ello hace que, aunque todavía varios de sus conceptos y su alcance legal sigan siendo discutidos, muchos sectores consideren que el conjunto de estas iniciativas conforman un itinerario de progreso. Y este, al margen de ciertas limitaciones, puede ser cualificado por la vía del diálogo, del análisis y, sobre todo, del fortalecimiento teórico y práctico de los estándares internacionales en materia de derechos humanos.

De hecho, sindicatos, ONG y organizaciones de derechos humanos, así como otros sectores de la sociedad civil, apelan hoy a las normas como un marco útil para clarificar las responsabilidades de empresas y gobiernos. Por su parte, no solo la Iniciativa para Líderes Empresariales para los Derechos Humanos - un programa liderado por empresas y presidido por la ex alta comisionada de las Naciones Unidas para los Derechos Humanos, Mary Robinson- comenzó a «testear» las normas ${ }^{26}$, sino que inversores con responsabilidad social — como los fondos de pensioneslas han invocado con cierta frecuencia en sus actividades, y más de una vez empresas que se adhieren a estándares de responsabilidad social empresarial han conducido intentos piloto para implementarlas.

Más allá de la recepción positiva que las normas suscitaron entre los sectores antes mencionados, el debate fue polarizándose y, finalmente, no logró alcanzar el peso político requerido para obtener el reconocimiento, la promoción ni la posterior adopción formal de sus principios centrales en el seno de las Naciones Unidas. Por el contrario, en 2005, las cosas parecieron volver al principio.

La Comisión de Derechos Humanos de las Naciones Unidas solicitó a su Secretario General que designara un representante especial sobre empresas y derechos humanos, y este designó al profesor de la Universidad de Harvard, John Ruggie, quien había participado de la creación del Pacto Mundial y en la Declaración del Milenio como asesor de Kofi Annan.

El representante especial del Secretario General fue encargado de elaborar informes para el Consejo de Derechos Humanos que le permitieran «señalar y aclarar normas uniformes sobre la responsabilidad empresarial y la rendición de cuentas [...] en la esfera de los derechos humanos», «precisar la función que incumbe a los Estados en la regulación y arbitraje efectivos» de las actividades empresariales, «investigar y aclarar las implicaciones [de] conceptos como 'complicidad'» e indicar algunas de

26 Véase, al efecto, BLIHR. Contribución a la Alta Comisionada de las Naciones Unidas para los Derechos Humanos relacionada a las "Responsabilidades de las empresas y otras empresas comerciales en la esfera de los derechos humanos", septiembre de 2004, en <www2.ohchr.org/ english/issues/globalization/business/docs/blihr.doc> (en inglés); BLIHR. Report 2: Work in Progress, 2004, en <http://www.blihr.org> (en inglés), en particular el capítulo «An overview of the BLIHR 'road-testing' of the norms»; y BLIHR, Report 3: Towards a "common framework» on business and human rights: identifying components, 2006, en <www.realizingrights.org/pdf/BLIHR3Report.pdf> (en inglés), en particular la sección «Learning from the content of the draft norms». 
las prácticas imperantes, cuando no «óptimas», de los Estados y de las empresas.

Un año después emitió su primer informe ${ }^{27}$; y, aunque sostuvo que las Normas de las Naciones Unidas contenían elementos útiles, dejó claramente sentada su decisión de descartarlas como base de su trabajo, y optó por la búsqueda de soluciones de carácter más bien pragmático.

En 2007, el señor Ruggie presentó un segundo informe ${ }^{28}$ a través del cual mapeó con fines ilustrativos las normas y los instrumentos internacionales existentes en el ámbito de la responsabilidad y de la rendición de cuentas de las empresas. Reconocía que la expansión de los mercados y el alcance transnacional de las actividades de muchas empresas no habían tenido como contrapartida una suficiente protección para las personas ni para las comunidades damnificadas ante los abusos de los derechos humanos por parte de aquellas. El informe reconocía también que, en gran medida, debido a la influencia de las empresas, muchas veces los Estados resultan incapaces o no tienen la voluntad de ofrecer protección contra los abusos que involucran a estas empresas.

El informe no entusiasmó a los grupos de la sociedad civil que venían trabajando sobre el tema. En particular, con respecto a las soluciones que frente a esta problemática proponía el informe, manifestaron directamente su preocupación ante el énfasis puesto por el representante especial para encontrar soluciones basadas en la autorregulación de las empresas $^{29}$, una vía que, como se señaló antes, no había mostrado gran eficacia para revertir los abusos que estas cometen contra los derechos humanos.

En junio de 2008, el representante especial presentó al Consejo de Derechos Humanos su cuarto informe, denominado «Proteger, respetar y reparar: un marco para las empresas y los derechos humanos» ${ }^{30}$. En este, quedó delineado, sin embargo, un marco conceptual que representaba un claro avance en sus propias concepciones. Se organiza alrededor de tres ejes:

i. Los Estados cuentan con la obligación de brindar protección contra los abusos de los derechos humanos por parte de

27 Véase el «Informe Provisional del Representante Especial del Secretario General sobre la Cuestión de los Derechos Humanos y las Empresas Transnacionales y otras Empresas Comerciales». E/ CN.4/2006/97, 22 de febrero de 2006. En <http://www2.ohchr.org/english/issues/globalization/ business/reports.htm>.

28 Véase "Las empresas y los derechos humanos: catálogo de las normas internacionales sobre responsabilidad y rendición de cuentas por actos cometidos por empresas: Informe del Representante Especial del Secretario General sobre la cuestión de los derechos humanos y las empresas transnacionales y otras empresas comerciales". A/HRC/4/035, 9 de febrero de 2007. En <http:// www2.ohchr.org/english/issues/trans_corporations/reports.htm>.

29 Véase la Intervención Conjunta de ONG en el Consejo de Derechos Humanos de la ONU, marzo de 2007. En <http://www.escrnet.org/actions_more/actions_more_show.htm?doc_ id=473679\&attribLang_id=13441>.

30 Véase «Proteger, respetar y reparar: un marco para las empresas y los derechos humanos». A/ HRC/8/5, 7 de abril de 2008. En <http://www.escr-net.org/usr_doc/Ruggie_2008InformeEDH_esp. $\mathrm{pdf}>$. 
terceros, incluidas las empresas, mediante políticas, regulación y sistemas de exigibilidad adecuados.

ii. Las empresas cuentan con la responsabilidad de respetar los derechos humanos - lo que el representante especial definió como algo que, en esencia, implica no abusar de los derechos humanos-.

iii. Las víctimas deben contar con mayor acceso a recursos efectivos que las protejan contra dichas violaciones.

En la medida en que el marco conceptual propuesto por el representante especial integró un conjunto de principios básicos que, durante muchos años, habían sido empleados por las ONG, los Estados y los académicos involucrados en el tema, el informe fue bien recibido por las asociaciones de empresarios, por los gobiernos y por los grupos de la sociedad civil.

Este reconoce que las dinámicas no reguladas en las que participan las empresas transnacionales poseen potenciales efectos negativos sobre todos los países, sobre todos los derechos humanos y sobre todos los sectores empresariales. Sostiene, además, que las empresas son responsables de respetar los derechos humanos en todas partes, y con ello refuerza la perspectiva que ya había sido adelantada por la Declaración Tripartita de la OIT, por las Normas de las Naciones Unidas y por los trabajos previos de la Oficina del Alto Comisionado de las Naciones Unidas para los Derechos Humanos.

En su cuarto y más reciente informe, «La empresa y los derechos humanos: la puesta en práctica del marco proteger, respetar y remediar» ${ }^{31}$, el representante especial reiteró el marco de tres pilares antes descrito y refirió el tipo de trabajo específico que tenía por objeto desarrollar durante los dos últimos años de su mandato, que vencerá en 2011.

\section{EL DEBER DE LAS EMPRESAS DE RESPETAR, PROTEGER Y REMEDIAR}

El marco conceptual elaborado por el representante especial sobre Empresas y Derechos Humanos de la ONU permite clarificar los deberes que el Estados y las empresas tienen en la esfera de los derechos humanos. Estos deberes se pueden resumir en los tres principios acotados al inicio de este artículo: proteger, respetar y remediar. Dichos principios componen un conjunto complementario en el que cada uno apoya a los demás hacia el progreso sostenible.

En cuanto al deber de proteger, el representante especial indica lo siguiente:

31 Véase «La empresa y los derechos humanos: la puesta en práctica del marco proteger, respetar y remediar». A/HRC/11/13, 22 de abril de 2009. En <http://www.reports-and-materials.org/ReporteRuggie-a-Consejo-DDHH-ONU-22-abr-2009.doc.>. 
[...] el derecho internacional establece firmemente que los Estados tienen el deber de proteger a los individuos bajo su jurisdicción contra violaciones de los derechos humanos no atribuibles al Estado y que esta obligación se extiende a la protección contra los abusos cometidos por entidades comerciales. El deber de proteger existe en el marco de la explicación detallada de los tratados fundamentales de derechos humanos de las Naciones Unidas dada por los órganos creados en virtud de esos tratados y también hay consenso en que existe en el marco del derecho internacional consuetudinario (Informe 2007).

Como consecuencia de lo anterior, los Estados tienen el deber de adoptar «todas las medidas necesarias para proteger frente a tales abusos». Particularmente, tienen «el deber de prevenir, investigar y castigar los abusos, y el deber de proporcionar vías de reparación» (Informe 2008) y, a la vez, deben «fomentar una cultura empresarial en la que el respeto de los derechos forme parte integrante de los negocios» (Informe 2008), que no solo deba extenderse a todas las empresas, con independencia de su dimensión, sino que abarque todos los derechos humanos.

Respetar los derechos humanos, dice el señor John Ruggie, «significa básicamente no infringir los derechos de los demás, es decir, no causar perjuicios» (Informe 2008), y este deber va de la mano con el principio de «no complicidad con abusos en derechos humanos».

El tercer principio, relativo al acceso a los remedios o recursos, alude a la garantía estatal de protección de los derechos humanos frente a infracciones o abusos, así como a la reparación de daños por parte tanto de actores estatales como no estatales, en particular cuando se trata de empresas: ello incluye medidas relativas a la investigación, la sanción y la reparación de los abusos producidos.

\section{ALGUNAS REFLEXIONES FINALES}

Ha dicho el representante especial del Secretario General de la ONU, señor Ruggie:

La causa última de la difícil situación de los derechos humanos en relación con las empresas reside en las lagunas de gestión debidas a la globalización, que han surgido entre el alcance y los efectos de las fuerzas y actores económicos, por una parte, y la capacidad de las sociedades para gestionar sus consecuencias adversas, por la otra. Estas lagunas de gestión crean un entorno permisivo para actos ilícitos de las empresas de todo tipo sin que haya sanciones o reparaciones adecuadas. Cómo reducir y en definitiva superar las lagunas relacionadas con los derechos humanos es nuestro problema fundamental ${ }^{32}$. 
En mi opinión, para reducir esas «lagunas de gestión», es necesario situar el énfasis en dos ejes claves: subrayar la primacía de los derechos humanos y reforzar los mecanismos que hagan efectiva la responsabilidad de las empresas.

En cuanto a lo primero, se debe clarificar que la primacía de los derechos humanos y los objetivos de desarrollo humano que de este principio derivan - a la luz de lo dispuesto en los artículos 55, 56 y 103 de la Carta de las Naciones Unidas-constituye el único marco de referencia que puede presidir la acción de los gobiernos y de las empresas en este ámbito.

Subrayar públicamente el carácter imperativo del principio de primacía de los derechos humanos ayudará a disipar las incongruencias verticales y horizontales en las que, con frecuencia, incurren los Estados al definir sus políticas de inversión y comercio. También permitirá someter los «derechos legales» de las empresas a este marco, incluidos los parámetros que presiden las instancias de arbitraje internacional y otros mecanismos ad hoc, creados con el mismo objeto en las agencias multilaterales y en los tratados de libre comercio.

Dicho principio posibilita, además, clarificar el marco jurídico al que deben someterse las empresas, pues precisa que este va más allá del cumplimiento de las leyes nacionales, y las obliga a sujetarse al Derecho internacional de los derechos humanos y al Derecho internacional humanitario. Permitirá, asimismo, clarificar que este deber alcanza a todos y no solo a un limitado conjunto de derechos.

La segunda cuestión clave tiene que ver con el hecho, ya advertido previamente, de que los instrumentos sobre RSE y derechos humanos desarrollados hasta hoy carecen de carácter imperativo, lo que induce a algunas empresas a suponer que no deben respetarlos obligatoriamente. Esto pone en evidencia que, más allá del valor que estos tengan en orden a clarificar las responsabilidades de las empresas en este ámbito, resultan insuficientes por sí solos para prevenir y evitar que ocurran abusos contra los derechos humanos. Ello pone de relieve la necesidad de fortalecer los mecanismos ya existentes de prevención, investigación y sanción relacionados con las violaciones a los derechos humanos cometidas por las empresas.

El Derecho internacional de los derechos humanos obliga a los Estados a poner énfasis en el deber estatal de prevención — como parte del deber de proteger-, sujetando la actuación de las empresas a estos estándares, investigando y sancionando cualquier violación en este campo, así como proporcionando remedios a las víctimas de estas violaciones. Los obliga, también, a dotar de efectividad al deber de asistencia y cooperación internacional requeridos para asegurar estos propósitos. 
Los Estados deben asegurar la existencia de mecanismos eficaces de reparación para impedir que los mecanismos no estatales socaven el acceso de las víctimas a la justicia en el nivel nacional. Deben, asimismo, cualificar los mecanismos ya existentes y estudiar la creación un mecanismo universal cuasi judicial que les permita interponer recursos que las protejan de tales violaciones.

En efecto, el derecho a interponer un recurso ha sido reconocido como un principio fundamental del Derecho internacional, conforme al cual resulta crucial que las instancias que se generen con este objeto expresen los principios de justicia y tengan la capacidad de proveer recursos efectivos para las víctimas, que deben poder ejercer este derecho en idóneas condiciones de accesibilidad, adecuación, efectividad y rapidez.

Dado que los derechos esenciales de los hombres y de las mujeres no nacen del hecho de ser nacionales de un determinado Estado, sino que tienen como fundamento los atributos de la persona humana, justifican una protección internacional, de naturaleza convencional coadyuvante o complementaria de la que ofrece el Derecho interno, ámbito en el que, como dice la DUDH, «deben ser protegidos por un régimen de Derecho, a fin de que la persona humana y los Pueblos [sic] no se vean compelidos al supremo recurso de la rebelión contra la tiranía y la opresión».

Para satisfacer este objetivo, deben darse pasos efectivos en orden a crear un mecanismo universal cuasi-judicial que posibilite el trámite de recursos en casos de violación de derechos humanos por las empresas. Un mecanismo no judicial, pero sí adjudicativo, que no remplace los mecanismos de queja existentes - tales como los que existen a nivel empresarial, los puntos nacionales de contacto de la OCDE, las instituciones nacionales de los derechos humanos, los códigos de conducta voluntarios, las iniciativas multipartes $\mathrm{u}$ otras generadas desde grupos liderados por inversionistas - , ni sustituya el importante rol de los mecanismos de justicia nacional.

Por el contrario, la propuesta de crear un mecanismo universal cuasijudicial para interponer recursos en casos de violación de derechos humanos por las empresas debe reforzar todos ellos mediante la creación de un órgano que recoja y desarrolle la experiencia ya lograda en los mecanismos de supervisión del cumplimiento de los estándares de derechos humanos a nivel universal y regional.

Un instrumento, en suma, que permita que los derechos dispongan de un medio que salvaguarde efectivamente la dignidad de las personas y sus derechos humanos. 